\title{
Biomarkers in Mood Disorders Among the Elderly: Can They Contribute to Diagnosis and Prognosis?
}

\author{
Antonio Lucio Teixeira • Andrea Wieck • \\ Breno Satler Diniz • Moises Evandro Bauer
}

Published online: 28 March 2012

(C) Springer Science+Business Media, LLC 2012

\begin{abstract}
Late-life depression is one of the most common neuropsychiatric disorders in the elderly population. Its clinical presentation is heterogeneous and has some distinctive features from depression in adults. In recent years, it has been demonstrated that patients with late-life depression present significant abnormalities in several neurobiological cascades. Among them, inflammatory, neuroendocrine, and neurotrophic cascades are of paramount importance. In this review, we revise the evidence of involvement of these cascades in the pathophysiology of late-life depression and the potential of the associated molecules (such as cytokines, neurotrophic factors, and hormones) as diagnostic and prognostic biomarkers. Despite the unequivocal advance in the understanding of its neurobiological basis, to date there is no sufficient evidence to support any
\end{abstract}

\footnotetext{
A. L. Teixeira $(\bowtie)$

Laboratório Interdisciplinar de Investigação Médica, Faculdade de Medicina, Universidade Federal de Minas Gerais, Avenida Alfredo Balena 190,

30130-100 Belo Horizonte, Minas Gerais, Brazil

e-mail: altexr@gmail.com
}

\author{
A. Wieck $\cdot$ M. E. Bauer \\ Laboratório de Imunologia do Envelhecimento, \\ Porto Alegre, Brazil \\ B. S. Diniz \\ Western Psychiatric Institute and Clinic, \\ University of Pittsburgh Medical Center, \\ Pittsburgh, PA, USA \\ B. S. Diniz \\ Department of Psychiatry, \\ University of Pittsburgh Medical School, \\ Pittsburgh, PA, USA
}

Instituto de Pesquisas Biomédicas, Faculdade de Biociências,

Pontifícia Católica Universidade do Rio Grande do Sul, biomarker of late-life depression. The search for valid biomarkers of late-life depression is warranted because they may contribute to correct diagnostic classification and to predict clinical outcome.

Keywords Aging - Major depression · Late-onset depression · Immunosenescence $\cdot$ Inflammaging · Cytokines - Adhesion molecules - Lymphocytes · Cortisol . Estrogen · Brain-derived neurotrophic factor · GSK-3beta

\section{Introduction}

Late-life depression (LLD) is one of the most common neuropsychiatric disorders in the elderly population [1]. LLD is a debilitating disorder and has a major impact on the patients' life. It is associated with worsened quality of life, loss of productivity, increased medical comorbidity, health service use, and higher risk of death [2]. The prevalence of LLD is variable and depends on several factors such as study setting, definition of depressive episode, measurement scales, and assessment of psychiatric and medical comorbidities. In community-dwelling elderly patients, prevalence of major depressive episode ranges from $4 \%$ to $22 \%[1,3]$. The prevalence of subsyndromal or minor depression and clinically relevant depressive symptoms are much more frequent than major depressive episode, ranging from $20 \%$ to $40 \%$ [4-6]. The most consistent risk factors for LLD episodes are older age, low educational attainment, presence of multiple medical and neurological comorbidities, living alone, and lack of social support [7].

In this article, we review recent advances in the understanding of biomarker changes in LLD and how they can inform about diagnosis, prognosis, and the neurobiological substrates for LLD. 


\section{Clinical Presentation of Late-Life Depression: Does Age of Onset Matter?}

The clinical presentation of LLD is heterogeneous and has some distinctive features from depressive episodes in adults. Complaints about sadness or downcast mood are less common in elderly persons. On the other hand, lack of energy and apathy along with somatic complaints and psychomotor retardation are prominent features of LLD. Psychotic phenomena, in particular nihilistic and guilty delusions, are also common in LLD $[8,9]$. Patients with LLD show significant global cognitive impairment $[10,11]$. Specific cognitive domains, such as executive function, short-term episodic memory, and processing of information speed, are particularly affected [11, 12].

Age of onset of LLD is an important feature of this condition and has a significant impact on clinical presentation. Patients are classified in early-onset LLD (EOD) if their first episode of major depression occurs at younger age or in late-onset LLD (LOD) if the first major depression episode occurs after age 65 years. Patients with LOD tend to have worse long-term prognosis and with increased comorbid cardiovascular disease as compared to EOD [13, 14]. Patients with LOD depict more severe and generalized cognitive deficits compromising most cognitive domains [11]. Executive functioning is particularly affected in LOD and may mediate the significant disability and functional impairment observed in these patients $[15,16,17 \cdot]$. Patients with EOD also may present significant cognitive impairment, notably of short-term episodic memory and information processing speed [11].

The heterogeneity of clinical manifestations and cognitive impairment patterns according to age of onset in LLD raised the question of whether this may reflect distinct underlying neurobiological substrates. Structural and functional neuroimaging studies have been shedding light on cerebral changes related to LLD. A large body of evidence suggests that patients with LLD show a significant higher frequency of cerebrovascular lesions (mainly periventricular and deep white matter hyperintensities and lacunar infarcts) and cerebral atrophy as compared to normal elderly control patients [18-21]. However, the pattern of cerebral structural changes is dependent on the age of onset of LLD. LOD patients usually show more significant cerebrovascular lesions as compared to patients with EOD [22-25]. These changes are most commonly located in the basal ganglia and in the fronto-subcortical white matter and seem to be associated with cognitive impairment, in particular executive dysfunction [25]. Given this close association between cerebral and cognitive changes, the term "vascular depression" has been coined to describe a subgroup of patients who presents LOD with history of cardio- and cerebrovascular diseases, accompanied by cerebrovascular lesions on the MRI and significant executive dysfunction [26-28, 29•].
Conversely, patients with EOD frequently show a significant regional cerebral atrophy, mostly in the hippocampal formation [30, 31]. Hippocampal atrophy correlates with the duration of the index depressive episode and the number of recurrent episodes [32,33], and might be a harbinger of future dementia in some patients [34]. Such structural changes are in parallel with progressive short-term episodic memory decline in EOD patients. The exact neurobiological mechanisms that lead to hippocampal atrophy in these patients are unknown, but is possibly related to the sum of multiple mechanisms including hypothalamic-pituitary-adrenal (HPA) axis dysfunction, high cortisolemia, and reduced neurotrophic support $[32,35]$.

\section{Inflammaging as a Pathogenic Mechanism in Late-Life Depression}

In the past two decades a growing body of evidence emerged suggesting that a deregulation of inflammatory control, with increased proinflammatory status, plays a significant role in the pathophysiology of depression across the lifespan.

Chronic low-grade inflammation (called "inflammaging") has been observed during human aging (particularly in unhealthy populations), and it has been associated with frailty, morbidity, and mortality in elderly patients [36]. Indeed, chronic inflammation is considered to be involved in the pathogenesis of major age-related diseases, including Alzheimer's disease (AD), atherosclerosis, diabetes, sarcopenia, cancer, and major depression [37]. Cytokines are well known to mediate central effects of peripheral inflammation, including sickness behavior and fever.

There are multiple mechanisms through which cytokines may lead to depression. One mechanism involves the metabolism of certain neurotransmitters, such as serotonin, dopamine, and glutamate [38••]. Tryptophan is the main component of serotonin synthesis. Once inflammatory cytokines reach the brain, the activation of various transcription factors (eg, mitogen-activated protein kinase and nuclear factor- $\mathrm{kB}$ ) takes place, leading to the activation of the enzyme indoleamine 2,3 dioxygenase (IDO). IDO is capable of metabolizing tryptophan into kynurenine, resulting in decreased synthesis of serotonin. Interestingly, patients undergoing interferon-alpha therapy for Hepatitis $\mathrm{C}$ virus infection or melanoma had decreased peripheral tryptophan levels and increased kynurenine levels concomitant with depressive symptoms development. Otherwise, kynurenine is preferentially converted into kynurenic acid in the brain, which interferes with the release of glutamate and dopamine. Dopamine also can be affected by inflammatory cytokines in a second way: cytokines reduce the levels of tetrahydro-biopterin $\left(\mathrm{BH}_{4}\right)$, which is an important co-factor 
for tyrosine hydroxylase, a rate-limiting enzyme for dopamine synthesis, resulting in decreased dopamine levels. Another mechanism involves the metabolism of neurotrophic factors like brain-derived neurotrophic factor (BDNF). Cytokines induce glutamate release by astrocytes and reduce the expression of glutamate transporters, reducing glutamatergic reuptake. The glutamate released by astrocytes has preferential access to extra-synaptic N-methyl-Daspartate receptors, which will reduce BDNF expression and decrease neurotrophic support. This reduced neurotrophic support will lead to increased neuronal susceptibility to oxidative stress.

Therefore, by modulating brain metabolism, "inflammaging" may be a relevant factor for the development of LLD. In addition, low-grade increases in levels of circulating tumor necrosis factor-alpha (TNF- $\alpha$ ), interleukin (IL)-6, soluble IL-2 receptor, and C-reactive protein (CRP) are strong predictors of all-cause mortality risk in several longitudinal studies of elderly cohorts. It is worth mentioning, however, that low-grade inflammation was not observed in strictly healthy elderly persons or centenarians, suggesting that "inflammaging" is more likely a feature of unsuccessful aging [39].

\section{Proinflammatory Profile in Late-Life Depression}

\section{Cytokines and Acute-Phase Proteins}

Cytokines and acute-phase proteins are important mediators of inflammatory response. These proteins can be readily assessed in different biological matrices and, thus, can be reliable biomarkers of inflammatory activity in an individual patient. Cytokines can be produced in the periphery and by central nervous system cells, such as activated microglia, exerting active biological effects in glial and neuronal functions [40]. Some of these effects are directly related to the physiopathology of depression, as previously mentioned, presenting also long-term consequences such as the emergence of neurodegenerative changes in the brain [41, 42].

Several studies have examined peripheral levels of cytokines and acute-phase proteins in patients with LLD. IL-1 $\beta$, a potent proinflammatory cytokine, was found significantly elevated in patients with LLD [43]. In a study carried out in our group, IL-1 $\beta$ was also significantly elevated in patients with LLD. Nonetheless, patients with EOD showed the highest plasma levels of IL-1 $\beta$ [44]. It is noteworthy that recurrent depressive episodes in adults was also associated with increased circulating levels of inflammatory markers like CRP [45], suggesting that recurrent depression is associated with cumulative proinflammatory burden.

TNF- $\alpha$ is the prototype proinflammatory cytokine and has been involved in the physiopathology of several chronic inflammatory disorders [46]. Despite studies in adult patients showing that TNF- $\alpha$ levels are significantly increased in patients with major depression [47••], the only study in LLD did not find significant differences between depressed patients and elderly control patients [48•]. Nonetheless, patients with LLD presented significant higher levels of soluble TNF- $\alpha$ receptor 2 (sTNF-R2, or p75), with no significant change in the levels of soluble TNF- $\alpha$ receptor 1 (sTNF-R1, or p55). These findings suggest that, despite patients with LLD not having significant changes in TNF$\alpha$ levels, they present with an abnormal regulation of the TNF- $\alpha$ signaling system during depression [48•]. In line with this, a recent study found that elevated serum levels of sTNF-R1 were associated with higher depressive symptoms, as measured by the Geriatric Depression Scale, in elderly patients 1 year after hip fracture [49]. Other proinflammatory cytokines and acute-phase proteins, such as IL6 , CRP, and $\alpha 1$-antichymotrypsin, are also increased in patients with LLD [49-51].

Overall, current research findings suggest that LLD is characterized by a deregulation of inflammatory control with increased proinflammatory status. Such changes tend to correlate with the severity of depressive symptoms in most studies and recurrent depressive episodes may have a cumulative proinflammatory effect. These proinflammatory changes are in excess of those expected during the senescence process, suggesting that abnormalities in the inflammatory control may play a significant role in the physiopathology of LLD.

Despite that these findings are relevant for the understanding of LLD neurobiological basis, they are nonspecific and do not help the diagnostic process for this disorder. Elevated inflammatory markers also have been reported in other major psychiatric disorders, such as bipolar disorder, schizophrenia, and obsessive-compulsive disorder [52-56]. Neurodegenerative disorders common in older patients, such as AD and Parkinson's disease, also show increased levels of proinflammatory cytokines $[57,58]$. It is worth highlighting the overlap of the profile of circulating biomarkers in LLD and $\mathrm{AD}$, preventing any differentiation between these two conditions based on them (see Table 1). In this context, CSF biomarkers may be of great value. Patients with other neurological diseases, such as multiple sclerosis, in which depressive symptoms are very common, also present with high levels of proinflammatory cytokines [59]. Nonetheless, a recent study combining nine serum biomarkers related to inflammatory, neurotrophic, and endocrine-metabolic cascades ( $\alpha 1$-antitrypsin, apolipoprotein CIII, BDNF, cortisol, epidermal growth factor, myeloperoxidase, prolactin, resistin, and sTNF-R2) showed a high accuracy for the diagnosis of major depression in younger adults $[60 \bullet \cdot$. This promising result needs to be confirmed by independent studies and it is uncertain whether it is valid 
Table 1 Peripheral biomarkers during aging, late-life depression, and Alzheimer's disease

\begin{tabular}{llll}
\hline Biomarkers & Aging & $\begin{array}{l}\text { Late-life } \\
\text { depression }\end{array}$ & $\begin{array}{l}\text { Alzheimer's } \\
\text { disease }\end{array}$ \\
\hline IL1- $\alpha$ & $\uparrow$ & $\uparrow$ & - \\
IL1- $\beta$ & $\uparrow$ & $\uparrow$ & $\uparrow$ \\
IL6 & $\uparrow$ & $\uparrow$ & $\uparrow$ \\
TNF- $\alpha$ & $\uparrow$ & $\uparrow$ & $\uparrow$ \\
NK cells & $\uparrow$ & $\uparrow$ & - \\
CD45RA+ (naive T cell) & $\downarrow$ & $\downarrow$ & $\downarrow$ \\
CD45RO+ (memory T cell) & $\uparrow$ & $\uparrow$ & - \\
CD8+CD28- (senescent cells) & $\uparrow$ & $\uparrow$ & $\downarrow$ \\
CD4/CD8 ratio & $\downarrow$ & $\uparrow$ & - \\
Adhesion molecules & $\uparrow$ & $\uparrow$ & $\uparrow$ \\
Sexual hormones & $\downarrow$ & $\downarrow$ & $\downarrow$ \\
BDNF & $\downarrow$ & $\downarrow$ & $\downarrow$ \\
Cortisol & $\uparrow$ & $\downarrow \uparrow$ & $\uparrow$ \\
\hline
\end{tabular}

$\uparrow$ increased; $\downarrow$ decreased; $I L$ interleukin; $T N F$ - $\alpha$ tumor necrosis factor alpha; $N K$ natural killer; $B D N F$ brain-derived neurotrophic factor

for LLD. The prognostic value of inflammation-related molecules in LLD has not been investigated yet.

\section{Adhesion Molecules}

Adhesion molecules play an important role in the inflammatory process. Once inflammation is triggered, upregulation of adhesion molecule genes takes places in endothelial and immune cells to facilitate leukocyte adhesion and migration to sites of inflammation. Data regarding levels of soluble adhesion molecules such as soluble intercellular adhesion molecule-1 (sICAM-1) and soluble vascular adhesion molecule-1 (sVCAM-1) are scarce and contradictory. Levels of sICAM-1 and sVCAM-1 were found elevated in the periphery of depressed elderly patients [61]. Postmortem studies also found increased expression of ICAM-1 and VCAM-1 in dorsolateral prefrontal cortex of depressed elderly patients [62]. Conversely, Thomas and colleagues [63] did not find any association between peripheral levels of sICAM-1 or sVCAM-1 and depression in elderly patients.

As observed for cytokines, sICAM-1 levels were also found increased in patients undergoing interferon- $\alpha$ treatment who developed major depression [64]. However, given the high frequency of ischemic changes during the aging process, it is difficult to define whether elevated levels of adhesion molecules are due to depression or not. Vascular depression theory postulates that LOD is associated with vascular and ischemic diseases to which adhesion molecules are considered good markers [61]. Accordingly, sICAM-1 levels were found elevated in individuals who developed major depression after an episode of acute coronary syndrome [65]. Interestingly, these levels were significantly higher in patients with no past history of depressive disorder than those who had [65]. Adhesion molecules are widely expressed on blood-brain barrier endothelial cells and can be related to its increased permeability during inflammatory processes, allowing cytokines to cross this barrier and exert its effects in the brain [61]. Together, these data point to a possible mechanism of action through which low-grade inflammation is involved in the development of LOD. The absence of studies assessing adhesion molecules levels in elderly patients diagnosed only with major depression (with no comorbidity) makes difficult to establish the precise role of these molecules as biomarkers and in the development of depressive states.

\section{Leukocyte Subsets}

Data regarding immune cell subsets in LLD are scarce. Changes in number and function of these cells would not be surprisingly, as they are responsible for the production of many cytokines observed altered in this context. However, cellular alterations are also common to the aging process itself, being hard to address the precise role of these putative biomarkers in LLD. Quantitative changes in leukocytes such as decreased in naïve T cells $\left(C D 45 \mathrm{RA}^{+}\right)$, increased number of memory T cells $\left(\mathrm{CD} 45 \mathrm{RO}^{+}\right)$, expansion of $\mathrm{CD} 8^{+} \mathrm{CD} 28^{-} \mathrm{T}$ cells (known as "senescent cells"), and increased natural killer (NK) cells have been observed during aging, particularly in elderly patients with increased depressive symptoms $[66,67]$. Increased $\mathrm{T}$ cell counts have been found in elderly depressed patients with no antidepressant treatment. NK-T cells, $\mathrm{CD} 8^{+}$cytotoxic $\mathrm{T}$ cells, and $\mathrm{CD} 4 / \mathrm{CD} 8$ ratio also have been found increased in this population [68]. Interestingly, when analyzing cell subsets from elderly depressed patients undergoing antidepressant treatment, the numbers of $\mathrm{CD} 8^{+}$ and NK-T cells did not differ from healthy individuals, while the $\mathrm{CD} 8 / \mathrm{CD} 4$ ratio is unaltered by antidepressant treatment $[12,13,68,69]$. More studies are needed to better understand the role of lymphoid subsets during aging and their possible role in LLD.

\section{Neuroendocrine Changes in Late-Life Depression}

\section{Hypothalamic-Pituitary-Adrenal Axis}

Current literature suggests that both major depression and aging are associated with significant activation of the HPA axis. LLD seems to follow the same scenario. Adults with major depression have shown increased plasma cortisol levels and enlarged anterior pituitary and adrenal glands, as well as failure to suppress cortisol levels following dexamethasone administration $[70,71]$. The increased HPA axis 
activity is thought to be related, at least in part, to diminished feedback regulation by endogenous glucocorticoids. Remarkably, successful antidepressant treatment is associated with normalization of feedback regulation of the HPA axis induced by glucocorticoids. Increased circulating cortisol might contribute to depression pathogenesis, as correction of hypercortisolemia with cortisol synthesis inhibitors also has been reported to ameliorate depression [72].

The HPA axis activation is regarded to be fundamental for the body to deal with changing environmental demands by increasing circulating energy substrates such as glucose and fatty acids. However, long-term increase in cortisol levels will negatively impact key brain areas involved with HPA axis feedback regulation (hippocampus and hypothalamus), impairing cognitive functions as well as leading to poorer cell-mediated immune responses. We have previously observed that lymphocytes of depressed patients are resistant to glucocorticoid treatment in vitro or in vivo [73, 74]. Ineffective action of glucocorticoids on target tissues could lead to immune activation as shown by chronic low-grade inflammation. Conversely, inflammation can stimulate the HPA axis via both a direct action of cytokines on the brain and by inducing glucocorticoid resistance [75]. Hypercortisolemia may have important long-term consequences for health, including higher allostatic load and accelerated aging. Indeed, depression has been associated with features of premature aging, and depressed individuals have a higher incidence of various agerelated diseases, including cardiovascular and cerebrovascular diseases, metabolic syndrome, and dementia [76].

Aging is also associated with significant activation of the HPA axis. We have observed that strictly healthy elderly persons had remarkably higher salivary cortisol but low dehydroepiandrosterone (DHEA) levels throughout the day compared to young adults [4]. These hormonal changes were found in parallel to age-related psychological distress, including increased depressive symptoms. DHEA is produced by the adrenal glands and is under the regulation of the HPA axis. It has been suggested that DHEA may antagonize many physiologic changes of cortisol, including enhancing immune functions [77]. The lack of appropriate DHEA levels could be a detrimental factor during aging. Interestingly, it has been shown that low DHEA levels were associated with depressed mood in older women [78] and DHEA supplementation significantly improved memory performance and depression ratings in elderly patients with depression [79].

The presence of depression seems to amplify the changes of the adrenal secretory pattern, already present in the physiological aging. Elderly patients with major depression or patients reporting increased self-reported ratings of depressive symptoms had increased nocturnal cortisol levels compared to healthy control patients $[80,81]$. In a recent large populationbased study, it was observed that LLD is associated with both hypo- and hypercortisolemia [82]. Nevertheless, only hypercortisolemic depression was associated with older age, cardiovascular diseases, and cognitive impairment [82].

Taken together, these studies suggest that changes in HPA axis molecules are not reliable biomarkers of LLD, but rather common phenomena observed during aging and depressive disorder.

\section{Sexual Hormones}

The role of sexual hormones in depression has long been addressed in an attempt to explain the higher susceptibility carried by women to develop mood disorders. Because depressive symptoms are common to women experiencing the low-estrogen phase of menstrual cycle, after childbirth, and during climacteric and menopause, it is believed that these hormones are related to physiopathology of depression in women [83-85].

During the climacteric phase (ie, the transition to menopause) the gradual decline in ovarian function leads to a reduction in sexual hormones production, including estrogen, testosterone, and progesterone. Estrogen reduction or deprivation can lead to many physiological changes, such as alterations in neuronal plasticity and neurotransmission [83]. More precisely, estrogen can modulate the serotonergic system, which is greatly involved in mood control. There is a high risk of depression during this phase, but several studies failed to establish any association between the levels of sexual hormones and development of depressive symptoms [83-88, 89•]. Therefore, sexual hormones do not seem useful as biomarkers in this context. Interestingly the longer climacteric phase, the higher risk of developing major depression [87, 89-91]. Moreover, studies described reduction in depressive symptoms after hysterectomy and oophorectomy in climacteric women, supporting the idea of hormonal fluctuations having worse effect on mood than low estrogen levels itself [28, 29•].

Hormonal replacement has been reported as increasing well-being in climacteric women, but its effects in ameliorating depressive symptoms remain controversial [84]. While women in estrogen therapy show a better response to fluoxetine treatment [84], postmenopausal women demonstrated increased risk to develop depressive disorders during hormonal replacement [85]. The development of major depression in menopausal state seems to be more common in women with a previous history of depressive disorder and to be related with psychosocial stress instead of sexual hormones [84-86].

\section{Neurotrophic Factors in Late-Life Depression}

Neurotrophic factors are a broad family of proteins that play several roles in the central nervous system, mainly 
maintenance of neuronal homeostasis, neuroprotection against insults, neuronal repair and regeneration, and synaptic formation and strengthening [92]. BDNF is the most abundant neurotrophic factor in the brain. Several studies found significant lower circulating levels of BDNF in patients with LLD as compared to nondepressed controls $[93,94]$. When studies stratified LLD according to the age of onset, patients with LOD had lower BDNF levels than those with EOD [95]. In addition, a recent study reported that older patients with subsyndromal depression showed levels of BDNF that were intermediate between patients with major depression and nondepressed control patients, suggesting a gradient effect [94]. In contrast, a communitybased study failed to find significant changes in BDNF levels in LLD [96]. Differences in samples, assessment of depressive symptoms, and severity of depressive symptoms may help to explain such conflicting results.

The dynamics of other neurotrophic factors have not been extensively explored in LLD. The glial cell line-derived neurotrophic factor (GDNF) plays a major role in the protection of catecholaminergic, dopaminergic, and cholinergic neurons [97] and axonal regeneration after injury [98]. Studies in LLD have reported contradictory results showing either elevated [99] or reduced GDNF levels [100] in LLD when compared to age- and sex-matched control patients. Likewise, studies with the nerve growth factor (NGF) also have reported contradictory findings in LLD, with one study reporting nonsignificant differences [96] and another reporting a significant reduction in LLD [101]. In the latter study, we found that older patients with previous history of depression, but who were euthymic and under antidepressant treatment at the time of laboratory assessment, also showed a significant reduction in NGF levels, comparable to those observed in patients with current depressive episode [101]. In light of these results, we hypothesized that lower NGF levels may represent a state marker of depressive disorder in elderly patients and also may indicate a significant disruption in the neurotrophic regulatory mechanism that takes place during the depressive episode and does not completely recover despite clinical improvement after treatment.

\section{Other Peripheral Biomarkers in Late-Life Depression}

Changes in other neurobiological cascades that may have physiopathologic and clinical relevance in LLD have been recently reported. Increased oxidative stress markers have been consistently reported in adult patients with major depression and bipolar disorder [102, 103]. In LLD, one study so far reported a significant increase in the peripheral levels of plasma 8-iso-prostaglandin F2- $\alpha$ (8-iso-PGF2- $\alpha$ ), a marker of oxidative damage, in patients with LLD [50]. Such changes were correlated to increased proinflammatory status in these patients, suggesting a significant crosstalk between oxidative damage and inflammatory status in LLD patients.

The glycogen synthase kinase-3 3 (GSK-3 $\beta$ ) is an intracellular enzyme that is involved in many cellular functions such as energy metabolism, structural plasticity, neurogenesis, and resilience to cellular injury [104]. Its activity is regulated by the phosphorylation of serine 9 epitope, rendering the enzyme inactive. As GSK-3 $\beta$ is involved in diverse cellular functions, it is plausible to hypothesize that this enzyme may be related to the physiopathology of mood and neurodegenerative disorders [105]. A recent study showed patients with LLD had lower levels of phosphorylated GSK- $3 \beta$ with no changes in total GSK $-3 \beta$ in platelets, suggesting that GSK- $3 \beta$ is possibly overactive in patients with LLD [106]. Moreover, these changes were markedly pronounced in patients with more severe cognitive impairment and depressive symptoms, indicating that GSK-3 $\beta$ overactivation is a state marker of more severe depressive episodes in older patients. Further studies are warranted to confirm this finding.

\section{Cerebrospinal Fluid Biomarkers in Late-Life Depression}

Few studies addressed changes in cerebrospinal fluid (CSF) biomarkers in LLD. Most studies focused on the accuracy of AD-related biomarkers (amyloid- $\beta_{42}$, total Tau, and phosphorylated Tau proteins) to differentiate between LLD and AD disease. In general, patients with LLD showed a pattern similar to those observed in elderly control patients when compared to $\mathrm{AD}$ profile that is characterized by low levels of total and phosphorylated Tau proteins and high levels of amyloid- $\beta_{42}$ [107-109]. Schneider and colleagues [110•] recently proposed that the only feasible tools to discriminate LLD and early AD (which is commonly associated with depressive symptoms) are the CSF biomarkers for AD. Their high negative predictive value could be regarded as inverse evidence ("negative depression biomarker") that LLD is the sole cause of cognitive symptoms in depressed elderly patients as opposed to prodromal or early Alzheimer's disease.

In a small study that included LLD patients and nondepressed elderly control patients, the former group showed higher levels of amyloid- $\beta_{42}$ and no difference in total and phosphorylated Tau proteins as compared to the latter group [111]. Nonetheless, LLD patients showed a higher CSF/ serum albumin ratio, suggesting dysfunction of the bloodbrain barrier possibly due to vascular processes. Another study showed increased CSF levels of a nonspecific marker of neurodegeneration, the neurofilament light protein, in LLD as compared to healthy control patients [112]. These results suggest that patients with LLD may develop nonspecific neurodegenerative and vascular changes during mood episodes that may render these patients more vulnerable to the development of dementia $[113,114]$. 


\section{Conclusions and Perspectives}

A growing body of evidence suggests that LLD patients present significant abnormalities in several neurobiological cascades, determining changes in peripheral and central nervous system biomarkers. These studies contributed to the understanding of the physiopathological features of LLD and its relationship with medical comorbidities and neurodegenerative and cerebrovascular disorders. However, they are much less informative regarding diagnosis, prognosis, and treatment selection for individual patients. To date, there are no sufficient data to support any biomarker as diagnostic or prognostic of LLD.

Advances in this field will be possible by integrating distinct approaches and taking into consideration diverse biomarkers derived from several neurobiological cascades involved in LLD. New strategies for biomarkers discovery and development, including the "-omics" (genomics, proteomics, metabolomics), new structural neuroimaging (iron imaging, microbleeds, tractography), and functional and molecular imaging techniques should be incorporated to long-term clinical and epidemiological studies to determine the diagnostic and prognostic values of different biomarkers. Moreover, these strategies should be systematically included in clinical trials to provide more specific (neurobiologicalbased) selection criteria for patients, and to predict responsiveness or refractoriness to treatment.

The identification of LLD biomarkers may contribute to the development of more specific and personalized interventions aiming not only at the treatment of current depressive episodes but also the prevention of adverse outcomes, mainly functional and cognitive decline that ultimately lead to clinical diagnosis of dementia.

Acknowledgments This work was supported by grants from the Conselho Nacional de Desenvolvimento Científico e Tecnológico (CNPq [ALT and MEB]) and the Coordenação de Aperfeiçoamento de Pessoal de Nível Superior (CAPES [AW]), Brazil.

Disclosures No potential conflicts of interest relevant to this article were reported.

\section{References}

Papers of particular interest, published recently, have been highlighted as:

- Of importance

•- Of major importance

1. Byers AL, Yaffe K, Covinsky KE, Friedman MB, Bruce ML. High occurrence of mood and anxiety disorders among older adults: the National Comorbidity Survey Replication. Arch Gen Psychiatry. 2010;67(5):489-96.

2. Alexopoulos GS, Borson S, Cuthbert BN, et al. Assessment of late life depression. Biol Psychiatry. 2002;52:164-74.
3. Blay SL, Andreoli SB, Fillenbaum GG, Gastal FL. Depression morbidity in later life: prevalence and correlates in a developing country. Am J Geriatr Psychiatry. 2007;15(9):790-9.

4. Castro-Costa E, Lima-Costa MF, Carvalhais S, Firmo JO, Uchoa E. Factors associated with depressive symptoms measured by the 12-item General Health Questionnaire in community-dwelling older adults (The Bambui Health Aging Study). Rev Bras Psiquiatr. 2008;30:104-9.

5. Barcelos-Ferreira R, Pinto Jr JA, Nakano EY, Steffens DC, Litvoc J, Bottino CM. Clinically significant depressive symptoms and associated factors in community elderly subjects from Sao Paulo, Brazil. Am J Geriatr Psychiatry. 2009;17(7):582-90.

6. Thielke SM, Diehr P, Unutzer J. Prevalence, incidence, and persistence of major depressive symptoms in the Cardiovascular Health Study. Aging Ment Health. 2010;14:168-76.

7. Barcelos-Ferreira R, Izbicki R, Steffens DC, Bottino CM. Depressive morbidity and gender in community-dwelling Brazilian elderly: systematic review and meta-analysis. Int Psychogeriatr. 2010;22(5):712-26.

8. Krishnan KR. Biological risk factors in late life depression. Biol Psychiatry. 2002;52(3):185-92.

9. Hybels CF, Blazer DG, Landerman LR, Steffens DC. Heterogeneity in symptom profiles among older adults diagnosed with major depression. Int Psychogeriatr. [Epub ahead of print] PMID: 21241529.

10. Kohler S, Thomas AJ, Barnett NA, O'Brien JT. The pattern and course of cognitive impairment in late-life depression. Psychol Med. 2010;40(4):591-602.

11. Herrmann LL, Goodwin GM, Ebmeier KP. The cognitive neuropsychology of depression in the elderly. Psychol Med. 2007;37:1693702 .

12. Butters MA, Whyte EM, Nebes RD, et al. The nature and determinants of neuropsychological functioning in late-life depression. Arch Gen Psychiatry. 2004;61:587-95.

13. Alexopoulos GS. Depression in the elderly. Lancet. 2005;365 (9475):1961-70.

14. Fiske A, Wetherell JL, Gatz M. Depression in older adults. Annu Rev Clin Psychol. 2009;5:363-89.

15. Alexopoulos GS, Kiosses DN, Heo M, Murphy CF, Shanmugham B, Gunning-Dixon F. Executive dysfunction and the course of geriatric depression. Biol Psychiatry. 2005;58(3):204-10.

16. Pereira FS, Yassuda MS, Oliveira AM, Forlenza OV. Executive dysfunction correlates with impaired functional status in older adults with varying degrees of cognitive impairment. Int Psychogeriatr. 2008;20:1104-15.

17. - Yen YC, Rebok GW, Gallo JJ, Jones RN, Tennstedt SL. Depressive symptoms impair everyday problem-solving ability through cognitive abilities in late life. Am J Geriatr Psychiatry. 2011;19(2):142-50. This is a large population-based study showing the negative impact of depressive symptoms on cognitive abilities and on functional status of patients with late-life depression.

18. Greenwald BS, Kramer-Ginsberg E, Krishnan KR, Ashtari M, Auerbach C, Patel M. Neuroanatomic localization of magnetic resonance imaging signal hyperintensities in geriatric depression. Stroke. 1998;29(3):613-7.

19. Lee SH, Payne ME, Steffens DC, et al. Subcortical lesion severity and orbitofrontal cortex volume in geriatric depression. Biol Psychiatry. 2003;54(5):529-33.

20. Taylor WD, Steffens DC, MacFall JR, et al. White matter hyperintensity progression and late-life depression outcomes. Arch Gen Psychiatry. 2003;60(11):1090-6.

21. O'Brien JT, Firbank MJ, Krishnan MS, et al. White matter hyperintensities rather than lacunar infarcts are associated with depressive symptoms in older people: the LADIS study. Am J Geriatr Psychiatry. 2006;14(10):834-41. 
22. Nebes RD, Reynolds CF, Boada F, et al. Longitudinal increase in the volume of white matter hyperintensities in late-onset depression. Int J Geriatr Psychiatry. 2002;17(6):526-30.

23. Hickie I, Scott E, Naismith S, et al. Late-onset depression: genetic, vascular and clinical contributions. Psychol Med. 2001;31 (8):1403-12.

24. Baldwin RC, O’Brien J. Vascular basis of late-onset depressive disorder. Br J Psychiatry. 2002;180:157-60.

25. Herrmann LL, Le Masurier M, Ebmeier KP. White matter hyperintensities in late life depression: a systematic review. J Neurol Neurosurg Psychiatry. 2008;79(6):619-24.

26. Alexopoulos GS, Meyers BS, Young RC, Campbell S, Silbersweig D, Charlson M. 'Vascular depression' hypothesis. Arch Gen Psychiatry. 1997;54(10):915-22.

27. Alexopoulos GS, Meyers BS, Young RC, Kakuma T, Silbersweig D, Charlson M. Clinically defined vascular depression. Am J Psychiatry. 1997;154(4):562-5.

28. Sneed JR, Roose SP, Sackeim HA. Vascular depression: a distinct diagnostic subtype? Biol Psychiatry. 2006;60(12):1295-8.

29. - Culang-Reinlieb ME, Johnert LC, Brickman AM, Steffens DC, Garcon E, Sneed JR. MRI-defined vascular depression: a review of the construct. Int J Geriatr Psychiatry. [Epub ahead of print]. PMID: 21192018. This article is a comprehensive review of the state-of-art of the vascular hypothesis in late-life depression.

30. Bell-McGinty S, Butters MA, Meltzer CC, Greer PJ, Reynolds $\mathrm{CF}$, Becker JT. Brain morphometric abnormalities in geriatric depression: long-term neurobiological effects of illness duration. Am J Psychiatry. 2002;159:1424-7.

31. Janssen J, Hulshoff Pol HE, de Leeuw FE, et al. Hippocampal volume and subcortical white matter lesions in late life depression: comparison of early and late onset depression. J Neurol Neurosurg Psychiatry. 2007;78:638-40.

32. Sheline YI, Gado MH, Kraemer HC. Untreated depression and hippocampal volume loss. Am J Psychiatry. 2003;160:1516-8.

33. Sheline YI, Wang PW, Gado MH, Csernansky JG, Vannier MW. Hippocampal atrophy in recurrent major depression. Proc Natl Acad Sci U S A. 1996;93:3908-13.

34. Steffens DC, Payne ME, Greenberg DL, et al. Hippocampal volume and incident dementia in geriatric depression. Am J Geriatr Psychiatry. 2002;10(1):62-71.

35. Dedovic K, Engert V, Duchesne A, et al. Cortisol awakening response and hippocampal volume: vulnerability for major depressive disorder? Biol Psychiatry. 2010;68(9):847-53 .

36. Franceschi C, Bonafe M, Valensin S, Olivieri F, De Luca M, Ottaviani E, et al. Inflamm-aging. An evolutionary perspective on immunosenescence. Ann N Y Acad Sci. 2000;908:244-54.

37. Hunt KJ, Walsh BM, Voegeli D, Roberts HC. Inflammation in aging part 2: implications for the health of older people and recommendations for nursing practice. Biol Res Nurs. 2010;11 (3):253-60.

38. •- Miller AH, Maletic V, Raison CL. Inflammation and its discontents: the role of cytokines in the pathophysiology of major depression. Biol Psychiatry. 2009;65(9):732-41. This review provides an excellent update on the role of inflammatory mechanisms in the pathophysiology of stress response and depression.

39. Luz C, Dornelles F, Preissler T, Collaziol D, Cruz I, Bauer ME. Impact of psychological and endocrine factors on cytokine production of healthy elderly people. Mech Ageing Dev. 2003;124:887-95.

40. Lee YB, Nagai A, Kim SU. Cytokines, chemokines, and cytokine receptors in human microglia. J Neurosci Res. 2002;69(1):94103.

41. Berk M, Kapczinski F, Andreazza AC, et al. Pathways underlying neuroprogression in bipolar disorder: focus on inflammation, oxidative stress and neurotrophic factors. Neurosci Biobehav Rev. 2011;35(3):804-17.
42. Loftis JM, Huckans M, Morasco BJ. Neuroimmune mechanisms of cytokine-induced depression: current theories and novel treatment strategies. Neurobiol Dis. 2010;37(3):519-33.

43. Thomas AJ, Davis S, Morris C, Jackson E, Harrison R, O'Brien JT. Increase in interleukin-1beta in late-life depression. Am J Psychiatry. 2005;162(1):175-7.

44. Diniz BS, Teixeira AL, Talib L, Gattaz WF, Forlenza O. Interleukin-1beta serum level is increased in antidepressantfree elderly depressed patients. Am J Geriatr Psychiatry. 2010;18:172-6.

45. Copeland WE, Shanahan L, Worthman C, Angold A, Costello EJ. Cumulative depression episodes predict later $\mathrm{C}$-reactive protein levels: a prospective analysis. Biol Psychiatry. 2012;71(1):15-21.

46. Chadwick W, Magnus T, Martin B, Keselman A, Mattson MP, Maudsley S. Targeting TNF-alpha receptors for neurotherapeutics. Trends Neurosci. 2008;31:504-11.

47. • Dowlati Y, Herrmann N, Swardfager W, et al. A meta-analysis of cytokines in major depression. Biol Psychiatry. 2010;67 (5):446-57. The authors performed a comprehensive metaanalysis of the literature that provides strong evidence of altered inflammatory response in major depression.

48. - Diniz BS, Teixeira AL, Talib LL, Mendonca VA, Gattaz WF, Forlenza OV. Increased soluble TNF receptor 2 in antidepressantfree patients with late-life depression. J Psychiatr Res. 2010;44 (14):917-20. This is the first study to show abnormal regulation of TNF-signaling system in late-life depression.

49. Matheny ME, Miller RR, Shardell MD, et al. Inflammatory cytokine levels and depressive symptoms in older women in the year after hip fracture: findings from the Baltimore Hip Studies. J Am Geriatr Soc. 2011;59(12):2249-55.

50. Dentino AN, Pieper CF, Rao MK, et al. Association of interleukin-6 and other biologic variables with depression in older people living in the community. J Am Geriatr Soc. 1999;47(1):6-11.

51. Dimopoulos N, Piperi C, Psarra V, Lea RW, Kalofoutis A. Increased plasma levels of 8-iso-PGF2alpha and IL-6 in an elderly population with depression. Psychiatry Res. 2008;161(1):59-66.

52. Rocha FF, Correa H, Teixeira AL. Obsessive-compulsive disorder and immunology: a review. Prog Neuropsychopharmacol Biol Psychiatry. 2008;32(5):1139-46.

53. Barbosa IG, Huguet RB, Mendonca VA, et al. Increased plasma levels of soluble TNF receptor I in patients with bipolar disorder. Eur Arch Psychiatry Clin Neurosci. 2011;261(2):139-43.

54. Brietzke E, Kauer-Sant'Anna M, Teixeira AL, Kapczinski F. Abnormalities in serum chemokine levels in euthymic patients with bipolar disorder. Brain Behav Immun. 2009;23(8):1079-82.

55. Fontenelle LF, Barbosa IG, Luna JV, de Sousa LP, Abreu MN, Teixeira AL. A cytokine study of adult patients with obsessivecompulsive disorder. Compr Psychiatry. [Epub ahead of print]. PMID: 22300901

56. Kunz M, Cereser KM, Goi PD, et al. Serum levels of IL-6, IL-10 and TNF-alpha in patients with bipolar disorder and schizophrenia: differences in pro- and anti-inflammatory balance. Rev Bras Psiquiatr. 2011;33(3):268-74.

57. Diniz BS, Teixeira AL, Ojopi EB, et al. Higher serum sTNFR1 level predicts conversion from mild cognitive impairment to Alzheimer's disease. J Alzheimers Dis. 2010;22(4):1305-11.

58. Forlenza OV, Diniz BS, Talib LL, et al. Increased serum IL-1beta level in Alzheimer's disease and mild cognitive impairment. Dement Geriatr Cogn Disord. 2009;28(6):507-12.

59. Wu GF, Alvarez E. The immunopathophysiology of multiple sclerosis. Neurol Clin. 2011;29(2):257-78.

60. •- Papakostas GI, Shelton RC, Kinrys G, et al. Assessment of a multi-assay, serum-based biological diagnostic test for major depressive disorder: a Pilot and Replication Study. Mol Psychiatry. [Epub ahead of print]. PMID: 22158016. This study showed that a 
biological test comprising the serum levels of nine biomarkers $(\alpha 1$ antitrypsin, apolipoprotein CIII, brain-derived neurotrophic factor, cortisol, epidermal growth factor, myeloperoxidase, prolactin, resistin, and soluble tumor necrosis factor alpha receptor type II) can differentiate major depression patients from nondepressed control patients with adequate sensitivity and specificity.

61. Dimopoulos N, Piperi C, Salonicioti A, Mitsonis C, Liappas I, Lea RW, et al. Elevation of plasma concentration of adhesion molecules in late-life depression. Int $\mathrm{J}$ Geriatr Psychiatry. 2006;21(10):965-71.

62. Thomas AJ, Ferrier IN, Kalaria RN, Davis S, O’Brien JT. Cell adhesion molecule expression in the dorsolateral prefrontal cortex and anterior cingulate cortex in major depression in the elderly. Br J Psychiatry. 2002;181:129-34.

63. Thomas AJ, Morris C, Davis S, Jackson E, Harrison R, O'Brien JT. Soluble cell adhesion molecules in late-life depression. Int Psychogeriatr. 2007;19(5):914-20.

64. Schaefer M, Horn M, Schmidt F, Schmid-Wendtner MH, Volkenandt M, Ackenheil M, et al. Correlation between sICAM-1 and depressive symptoms during adjuvant treatment of melanoma with interferonalpha. Brain Behav Immun. 2004;18(6):555-62.

65. Lesperance F, Frasure-Smith N, Theroux P, Irwin M. The association between major depression and levels of soluble intercellular adhesion molecule 1 , interleukin-6, and C-reactive protein in patients with recent acute coronary syndromes. Am J Psychiatry. 2004;161(2):271-7.

66. Bauer ME. Stress, glucocorticoids and ageing of the immune system. Stress. 2005;8(1):69-83.

67. Pawelec G, Barnett Y, Forsey R, Frasca D, Globerson A, McLeod J, et al. T cells and aging. Front Biosci. 2002;7:d1056-183.

68. Bouhuys AL, Flentge F, Oldehinkel AJ, van den Berg MD. Potential psychosocial mechanisms linking depression to immune function in elderly subjects. Psychiatry Res. 2004;127(3):237-45.

69. Flentge F, van den Berg MD, Bouhuys AL, The HT. Increase of NK-T cells in aged depressed patients not treated with antidepressive drugs. Biol Psychiatry. 2000;48(10):1024-7.

70. Dinan TG. Glucocorticoids and the genesis of depressive illness. A psychobiological model. Br J Psychiatry. 1994;164(3):365-71.

71. Pariante CM, Lightman SL. The HPA axis in major depression: classical theories and new developments. Trends Neurosci. 2008;31(9):464-8.

72. O'Dwyer AM, Lightman SL, Marks MN, Checkley SA. Treatment of major depression with metyrapone and hydrocortisone. J Affect Disord. 1995;33(2):123-8.

73. Bauer ME, Papadopoulos A, Poon L, Perks P, Lightman S, Checkley $\mathrm{S}$, et al. Altered glucocorticoid immunoregulation in treatment resistant depression. Psychoneuroendocrinol. 2003;28:49-65.

74. Bauer ME, Papadopoulos A, Poon L, Perks P, Lightman S, Checkley S, et al. Dexamethasone-induced effects on lymphocyte distribution and expression of adhesion molecules in treatment resistant major depression. Psychiatry Res. 2002;113:1-15.

75. Raison CL, Capuron L, Miller AH. Cytokines sing the blues: inflammation and the pathogenesis of depression. Trends Immunol. 2006;27(1):24-31.

76. Wolkowitz OM, Epel ES, Reus VI, Mellon SH. Depression gets old fast: do stress and depression accelerate cell aging? Depress Anxiety. 2010;27(4):327-38.

77. Hechter O, Grossman A, Chatterton RT. Relationship of dehydroepiandrosterone and cortisol in disease. Med Hypotheses. 1997;49(1):85-91.

78. Barrett-Connor E, von Muhlen D, Laughlin GA, Kripke A. Endogenous levels of dehydroepiandrosterone sulfate, but not other sex hormones, are associated with depressed mood in older women: the Rancho Bernardo Study. J Am Geriatr Soc. 1999;47(6):685-91.
79. Wolkowitz OM, Reus VI, Roberts E, Manfredi F, Chan T, Raum WJ, et al. Dehydroepiandrosterone (DHEA) treatment of depression. Biol Psychiatry. 1997;41(3):311-8.

80. Ferrari E, Mirani M, Barili L, Falvo F, Solerte SB, Cravello L et al. Cognitive and affective disorders in the elderly: a neuroendocrine study. Arch Gerontol Geriatr Suppl. 2004;(9):171-82.

81. Balardin JB, Vedana G, Luz C, Bromberg E. Subjective mild depressive symptoms are associated with abnormal diurnal cycle of salivary cortisol in older adults. J Geriatr Psychiatry Neurol. 2011;24(1):19-22.

82. Bremmer MA, Deeg DJ, Beekman AT, Penninx BW, Lips P, Hoogendijk WJ. Major depression in late life is associated with both hypo- and hypercortisolemia. Biol Psychiatry. 2007;62 (5):479-86.

83. Al-Azzawi F, Palacios S. Hormonal changes during menopause. Maturitas. 2009;63(2):135-7.

84. Pearlstein T, Rosen K, Stone AB. Mood disorders and menopause. Endocrinol Metab Clin North Am. 1997;26(2):279-94.

85. Llaneza P, Garcia-Portilla MP, Llaneza-Suarez D, Armott B, Perez-Lopez FR. Depressive disorders and the menopause transition. Maturitas. 2012;71(2):120-30.

86. Cohen LS, Soares CN, Vitonis AF, Otto MW, Harlow BL. Risk for new onset of depression during the menopausal transition: the Harvard study of moods and cycles. Arch Gen Psychiatry. 2006;63(4):385-90.

87. Freeman EW, Sammel MD, Liu L, Gracia CR, Nelson DB, Hollander L. Hormones and menopausal status as predictors of depression in women in transition to menopause. Arch Gen Psychiatry. 2004;61(1):62-70.

88. Schmidt PJ, Haq N, Rubinow DR. A longitudinal evaluation of the relationship between reproductive status and mood in perimenopausal women. Am J Psychiatry. 2004;161(12):2238-44.

89. - Bromberger JT, Schott LL, Kravitz HM, Sowers M, Avis NE, Gold EB et al. Longitudinal change in reproductive hormones and depressive symptoms across the menopausal transition: results from the Study of Women's Health Across the Nation (SWAN). Arch Gen Psychiatry. 2010;67(6):598-607. This longitudinal study provides relevant evidence on the association between sex hormone fluctuations and the development of depression in women during menopausal transition.

90. Avis NE, Brambilla D, McKinlay SM, Vass K. A longitudinal analysis of the association between menopause and depression. Results from the Massachusetts Women's Health Study. Ann Epidemiol. 1994;4(3):214-20.

91. Maartens LW, Knottnerus JA, Pop VJ. Menopausal transition and increased depressive symptomatology: a community based prospective study. Maturitas. 2002;42(3):195-200.

92. Tapia-Arancibia L, Aliaga E, Silhol M, Arancibia S. New insights into brain BDNF function in normal aging and Alzheimer disease. Brain Res Rev. 2008;59(1):201-20.

93. Chu CL, Liang CK, Chou MY, et al. Decreased plasma brainderived neurotrophic factor levels in institutionalized elderly with depressive disorder. J Am Med Dir Assoc. [Epub ahead of print].PMID: 21944169.

94. Shi Y, You J, Yuan Y, Zhang X, Li H, Hou G. Plasma BDNF and tPA are associated with late-onset geriatric depression. Psychiatry Clin Neurosci. 2010;64:249-54.

95. Diniz B, Teixeira A, Talib L, Mendonça V, Gattaz W, Forlenza O. Serum brain-derived neurotrophic factor level is reduced in antidepressant-free patients with late-life depression. World J Biol Psychiatry. 2010;11(3):550-5.

96. Ziegenhorn AA, Schulte-Herbröggen O, Danker-Hopfe H, et al. Serum neurotrophins-a study on the time course and influencing factors in a large old age sample. Neurobiol Aging. 2007;28:1436-45.

97. Pascual A, Hidalgo-Figueroa M, Piruat JI, Pintado CO, GomezDiaz R, Lopez-Barneo J. Absolute requirement of GDNF for 
adult catecholaminergic neuron survival. Nat Neurosci. 2008;11 (7):755-61.

98. Straten G, Schmeer C, Kretz A, et al. Potential synergistic protection of retinal ganglion cells from axotomy-induced apoptosis by adenoviral administration of glial cell line-derived neurotrophic factor and X-chromosome-linked inhibitor of apoptosis. Neurobiol Dis. 2002;11(1):123-33.

99. Wang X, Hou Z, Yuan Y, et al. Association study between plasma GDNF and cognitive function in late-onset depression. J Affect Disord. 2011;132(3):418-21.

100. Diniz BS, Teixeira AL, Miranda AS, Talib LL, Gattaz WF, Forlenza OV. Circulating Glial-derived neurotrophic factor is reduced in latelife depression. J Psychiatr Res. 2012;46(1):135-9.

101. Diniz BS, Teixeira AL, Machado-Vieira R, Talib LL, Gattaz WF, Forlenza OV. Reduced serum Nerve Growth Factor in patients with late-life depression. Am J Geriatr Psychiatry. 2012 [in press].

102. Maes M, Galecki P, Chang YS, Berk M. A review on the oxidative and nitrosative stress (O\&NS) pathways in major depression and their possible contribution to the (neuro)degenerative processes in that illness. Prog Neuropsychopharmacol Biol Psychiatry. 2011;35(3):676-92.

103. Steckert AV, Valvassori SS, Moretti M, Dal-Pizzol F, Quevedo J. Role of oxidative stress in the pathophysiology of bipolar disorder. Neurochem Res. 2010;35(9):1295-301.

104. Peineau S, Bradley C, Taghibiglou C, et al. The role of GSK-3 in synaptic plasticity. Br J Pharmacol. 2008;153 Suppl 1:S428-437.

105. Jope RS, Roh MS. Glycogen synthase kinase-3 (GSK3) in psychiatric diseases and therapeutic interventions. Curr Drug Targets. 2006;7:1421-34.

106. Diniz BS, Talib LL, Joaquim HP, de Paula VR, Gattaz WF, Forlenza OV. Platelet GSK3B activity in patients with late-life depression: marker of depressive episode severity and cognitive impairment? World J Biol Psychiatry. 2011;12(3):216-22.

107. Blennow K. Cerebrospinal fluid protein biomarkers for Alzheimer's disease. NeuroRx. 2004;1:213-25.

108. Buerger K, Zinkowski R, Teipel SJ, et al. Differentiation of geriatric major depression from Alzheimer's disease with CSF tau protein phosphorylated at threonine 231. Am J Psychiatry. 2003;160:376-9.

109. Schönknecht P, Pantel J, Kaiser E, Thomann P, Schröder J. Increased tau protein differentiates mild cognitive impairment from geriatric depression and predicts conversion to dementia. Neurosci Lett. 2007;416:39-42.

110. - Schneider B, Prvulovic D, Oertel-Knochel V, Knochel C, Reinke B, Grexa M, Weber B, Hampel H. Biomarkers for major depression and its delineation from neurodegenerative disorders. Prog Neurobiol. 2011;95:703-17. The authors revise the literature on biomarkers for major depression and conclude that there is no positive diagnostic depression biomarker.

111. Gudmundsson P, Skoog I, Waern M, et al. The relationship between cerebrospinal fluid biomarkers and depression in elderly women. Am J Geriatr Psychiatry. 2007;15(10):832-8.

112. Gudmundsson P, Skoog I, Waern M, et al. Is there a CSF biomarker profile related to depression in elderly women? Psychiatry Res. 2010;176(2-3):174-8.

113. Butters MA, Young JB, Lopez O, et al. Pathways linking late-life depression to persistent cognitive impairment and dementia. Dialogues Clin Neurosci. 2008;10(3):345-57.

114. Ownby RL, Crocco E, Acevedo A, John V, Loewenstein D. Depression and risk for Alzheimer disease: systematic review, meta-analysis, and metaregression analysis. Arch Gen Psychiatry. 2006;63:530-8. 